Article

\title{
Atypical Bacilliredoxin AbxC Plays a Role in Responding to Oxidative Stress in Radiation-Resistant Bacterium Deinococcus radiodurans
}

\author{
Soyoung Jeong ${ }^{1,2} \mathbb{D}^{\mathbb{D}}$, Jong-Hyun Jung ${ }^{1,3}$, Min-Kyu Kim $^{1} \mathbb{D}$, Arjan de Groot ${ }^{4} \mathbb{D}$, Laurence Blanchard ${ }^{4} \mathbb{D}$, \\ Sangryeol Ryu ${ }^{2} \mathbb{D}$, Yong-Sun Bahn ${ }^{5, * \mathbb{D}}$ and Sangyong $\operatorname{Lim}^{1,3, * \mathbb{D}}$
}

1 Radiation Research Division, Korea Atomic Energy Research Institute, Jeongeup 56212, Korea; soyoung@kaeri.re.kr (S.J.); jungjh83@kaeri.re.kr (J.-H.J.); mkkim@kaeri.re.kr (M.-K.K.)

2 Department of Food and Animal Biotechnology, Research Institute of Agriculture and Life Sciences, Seoul National University, Seoul 08826, Korea; sangryu@snu.ac.kr

3 Department of Radiation Science and Technology, University of Science and Technology, Daejeon 34113, Korea

4 Molecular and Environmental Microbiology Team, Aix Marseille Univ, CEA, CNRS, BIAM, 13108 Saint Paul-Lez-Durance, France; nicolaas.degroot@cea.fr (A.d.G.); laurence.blanchard@cea.fr (L.B.)

5 Department of Biotechnology, College of Life Science and Biotechnology, Yonsei University, Seoul 03722, Korea

* Correspondence: ysbahn@yonsei.ac.kr (Y.-S.B.); saylim@kaeri.re.kr (S.L.)

\section{check for} updates

Citation: Jeong, S.; Jung, J.-H.; Kim, M.-K.; de Groot, A.; Blanchard, L.;

Ryu, S.; Bahn, Y.-S.; Lim, S. Atypical Bacilliredoxin AbxC Plays a Role in Responding to Oxidative Stress in Radiation-Resistant Bacterium Deinococcus radiodurans. Antioxidants 2021, 10, 1148. https://doi.org/ 10.3390/antiox10071148

Academic Editors: Luis M. Mateos and Michal Letek

Received: 13 June 2021

Accepted: 16 July 2021

Published: 20 July 2021

Publisher's Note: MDPI stays neutral with regard to jurisdictional claims in published maps and institutional affiliations.

Copyright: (c) 2021 by the authors. Licensee MDPI, Basel, Switzerland. This article is an open access article distributed under the terms and conditions of the Creative Commons Attribution (CC BY) license (https:/ / creativecommons.org/licenses/by/ $4.0 /)$.

\begin{abstract}
Deinococcus radiodurans is a robust bacterium with extraordinary resistance to ionizing radiation and reactive oxygen species (ROS). D. radiodurans produces an antioxidant thiol compound called bacillithiol (BSH), but BSH-related enzymes have not been investigated. The D. radiodurans mutant lacking $b s h A\left(d r \_1555\right)$, the first gene of the BSH biosynthetic pathway, was devoid of BSH and sensitive to hydrogen peroxide $\left(\mathrm{H}_{2} \mathrm{O}_{2}\right)$ compared to the wild-type $D$. radiodurans strain. Three bacilliredoxin (Brx) proteins, BrxA, B, and C, have been identified in BSH-producing bacteria, such as Bacillus. D. radiodurans possesses DR_1832, a putative homolog of BrxC. However, because DR_1832 contains a novel signature motif (TCHKT) and a C-terminal region similar to the colicin-like immunity domain, we named it $\mathrm{AbxC}$ (atypical BrxC). The deletion of $a b x C$ also sensitized cells to $\mathrm{H}_{2} \mathrm{O}_{2}$. AbxC exhibited peroxidase activity in vitro, which was linked to nicotinamide adenine dinucleotide phosphate (NADPH) oxidation via the BSH disulfide reductase DR_2623 (DrBdr). AbxC proteins were present mainly as dimers after exposure to $\mathrm{H}_{2} \mathrm{O}_{2}$ in vitro, and the oxidized dimers were resolved to monomers by the reaction coupled with $\mathrm{BSH}$ as an electron donor, in which DrBdr transported reducing equivalents from NADPH to AbxC through BSH recycling. We identified $25 \mathrm{D}$. radiodurans proteins that potentially interact with $\mathrm{AbxC}$ using AbxC-affinity chromatography. Most of them are associated with cellular metabolisms, such as glycolysis and amino acid biosynthesis, and stress response. Interestingly, $\mathrm{AbxC}$ could bind to the proposed peroxide-sensing transcription regulator, $\mathrm{DrOxyR}$. These results suggest that $\mathrm{AbxC}$ may be involved in the $\mathrm{H}_{2} \mathrm{O}_{2}$ signaling mechanism mediated by DrOxyR.
\end{abstract}

Keywords: Deinococcus radiodurans; oxidative stress; bacilliredoxin; bacillithiol; DR_1832

\section{Introduction}

Reactive oxygen species (ROS) are harmful byproducts of aerobic metabolism. ROS include superoxide anions $\left(\mathrm{O}_{2}{ }^{\bullet-}\right)$, hydrogen peroxide $\left(\mathrm{H}_{2} \mathrm{O}_{2}\right)$, and hydroxyl radicals $(\bullet \mathrm{OH})$, which have inherent chemical reactivity [1]. Oxidative stress caused by excess ROS generation leads to damage to cellular components, including lipids, proteins, and DNA [2]. To cope with the adverse effects of ROS, bacteria have evolved elaborate antioxidant systems [2]. These include ROS scavenging enzymes, such as catalase (CAT), superoxide dismutase (SOD), and alkyl hydroperoxide reductase (AhpCF), and redox-active enzymes such as thioredoxin (Trx) and glutaredoxin (Grx) [3,4]. Trx acts as an efficient thiol-disulfide 
reductant, which provides reducing equivalents to peroxiredoxin (Prx), which in turn acts as a peroxidase capable of catalyzing $\mathrm{H}_{2} \mathrm{O}_{2}$ [5].

Deinococcus radiodurans is well known for its extreme resistance to ionizing radiation (IR). Since IR exposure leads to ROS production, resulting in damage to cellular macromolecules, $D$. radiodurans is also resistant to oxidative stress [6]. D. radiodurans encodes three SODs (DR_1279, DR_1546, and DR_A0202), two CATs (DR_1998 and DR_A0259) and four Prxs (DR_0846, DR_1208, DR_1209, and DR_2242), among which DR_1279 (named SodA) and DR_1998 (named KatE1) are constitutively present at high levels [7,8]. Alkyl hydroperoxide reductase $\mathrm{C}(\mathrm{AhpC})$ belongs to the typical 2-Cys Prx with two highly conserved cysteine residues: $\mathrm{N}$-terminal peroxidatic CysP and C-terminal resolving CysR [9]. In D. radiodurans, AhpE (DR_2242), classified as atypical 1-Cys Prx containing only the CysP (lost the CysR), was detected with the AhpD-like protein (DR_1765), which protects cells from oxidative stress as a substitute for AhpF $[10,11]$. D. radiodurans possesses two Trxs (DR_0944 and DR_A0164) with the classic active site motif CGPC. DR_A0164 is reduced by $D$. radiodurans Trx reductase (TrxR; DR_1982), which can utilize only NADPH for activity [12]. DR_0846 is a Trx-dependent PrxQ, a homolog of bacterioferritin comigratory protein (BCP), which contains the two closely situated Cys residues (CXXXXC), and it functions as a molecular chaperone as well as a peroxidase [13].

Most aerobic organisms generate low-molecular-weight thiols (LMW thiols) such as glutathione (GSH), mycothiol (MSH), and bacillithiol (BSH), which are involved in the maintenance of cellular redox potentials and the protection of cells from a variety of reactive chemical and electrophilic species [14]. The best studied LMW thiol is the tripeptide GSH present in all eukaryotes and Gram-negative bacteria [15]. However, some Gram-positive Firmicutes such as Bacillus and Staphylococcus species and D. radiodurans lack GSH and instead produce $\mathrm{BSH}$, an $\alpha$-anomeric glycoside of L-cysteinyl-D-glucosamine with L-malic acid, which is functionally analogous to GSH [16]. Under oxidizing conditions, BSH forms BSH disulfide (BSSB), and the flavine adenine dinucleotide (FAD) cofactor-containing BSSB reductase Bdr (previously named YpdA) reverts it from its oxidized form using NADPH [17,18]. BSH also forms mixed disulfides with protein thiols, termed $S$-bacillithiolation, as a means of modulating or protecting protein activity against over-oxidation, and its reversal is catalyzed by bacilliredoxin (Brx) proteins [19]. In Bacillus subtilis, the redox sensitive organic hydroperoxide repressor (OhrR) is bacillithiolated in response to both cumene hydroperoxide $(\mathrm{CHP})$ and sodium hypochlorite $(\mathrm{NaOCl})$ treatment, suggesting a function for BSH in redox sensing $[15,19]$. Three Brx proteins have been identified in BSH-producing bacteria: YphP (renamed BrxA), YqiW (BrxB), and YtxJ (BrxC) (Figure 1A). BrxA and BrxB are paralogs of the DUF1094 family with an unusual CXC redox motif, which is different from the classical redox active CXXC motif found in Trx or Grx. The function of BrxA and $\mathrm{BrxB}$ in protein de-bacillithiolation has been demonstrated for the $S$-bacillithiolated $\mathrm{OhrR}$ and two metabolic enzymes, methionine synthase MetE and glyceraldehyde-3-phosphate dehydrogenase Gap, in B. subtilis or S. aureus [20,21]. Both BrxA and BrxB likely use a monothiol mechanism to reduce $S$-bacillithiolated proteins, in which the N-terminal Cys thiolate of the Brx CGC motif attacks the $S$-bacillithiolated protein, resulting in the reduction of the mixed disulfide and formation of an S-bacillithiolated Brx (Brx-SSB). Brx-SSB is then reduced by BSH, leading to BSSB formation, which is subsequently reduced by Bdr with electrons from NADPH [17]. BrxC belonging to the Trx-like protein DUF2847 family is a monothiol Brx with the active site Cys located in a conserved TCPIS motif reminiscent of that found in monothiol Grx [12,22]. Recently, the B. subtilis BrxC protein has been shown to catalyze the de-bacillithiolation of BrxB and Bdr in vitro and GapDH in vivo [23]. 
A

YphP
$(\mathrm{BrxA})$

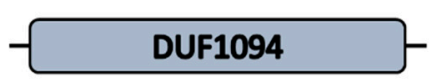

YqiW

(BrxB)
DUF1094

\section{YtxJ}

$(\mathrm{BrxC})$

DUF2847

DR_1832

(AbxC)

DUF2847

Colicin_immun

B

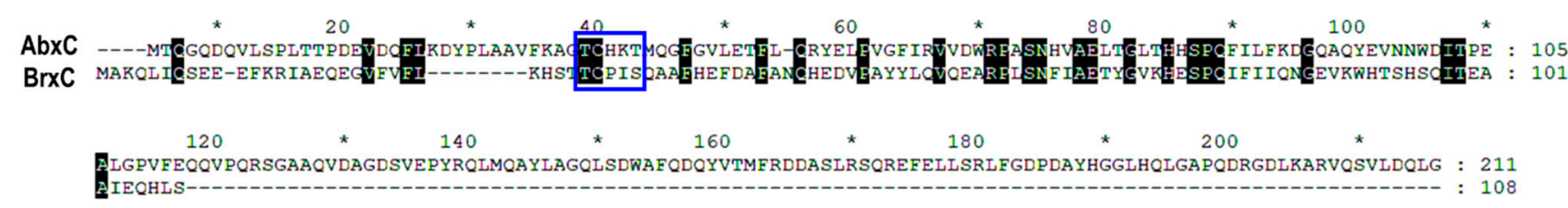

Figure 1. Comparison of bacilliredoxin (Brx) proteins from Bacillus subtilis and DR_1832 from Deinococcus radiodurans. (A) Schematic comparison of the domain structures of Brxs and atypical BrxC (AbxC). The C-terminal extended region (colicin_immun) of DR_1832 (atypical BrxC; AbxC) has similarity with bacterial self-protective colicin-like immunity domain (PF09204). (B) Comparison of amino acid sequences of AbxC and B. subtilis BrxC. Alignment was performed using Clustal Omega, and protein sequences were retrieved from the Uniprot database (www.uniprot.org. Accessed 8 June 2021): Q9RTD3_DEIRA (DR_1832) and YtxJ_BACSU (BrxC). White letters on black shading represent 100\% identity. The blue line box indicates the TCHKT and TCPIS motif conserved in AbxC and BrxC, respectively.

D. radiodurans encodes a putative homolog of Bdr (DR_2623), which shows 39\% and $35 \%$ identities with B. subtilis and S. aureus Bdr proteins, respectively [10]. The FAD-binding domain of Bdr contains the canonical glycine-rich signature sequence motif GXGXXG [24], which is conserved in DR_2623 (Figure S1). Regarding Brx, D. radiodurans possesses only the BrxC-type protein DR_1832 [12]. The DUF2847 domains of DR_1832 and B. subtilis BrxC share $25.24 \%$ identity. However, DR_1832 is longer than BrxC because of the presence of a C-terminal region that has similarity with the bacterial self-protective colicin-like immunity domain (PF09204) (Figure 1A), and the TCPIS motif observed in BrxC is replaced with TCHKT in DR_1832 (Figure 1B). The basic local alignment search tool for proteins (BLASTP) revealed that all deinococcal DR_1832 homologs have the C-terminal extension (data not shown), and the signature motif TCHKT is strictly conserved in all of these homologs (Figure S2). Therefore, DR_1832 was named AbxC (atypical BrxC). In this study, we investigated AbxC biochemically to establish a functional AbxC/BSH/DR_2623/NADPH redox cycle and found that $\mathrm{AbxC}$ exerts BSH-dependent peroxidase activity and interacts with the proposed D. radiodurans peroxide responsive regulator DrOxyR.

\section{Materials and Methods}

\subsection{Culture Conditions}

Deinococcus radiodurans $\mathrm{R} 1$ strain (ATCC13939) and its isogenic mutant strains were cultivated at $30{ }^{\circ} \mathrm{C}$ in TGY broth ( $0.5 \%$ tryptone, $0.1 \%$ glucose, and $0.3 \%$ yeast extract) with aeration or on TGY plates supplemented with $1.5 \%$ Bacto-agar. Escherichia coli strain $\mathrm{DH} 10 \mathrm{~B}$ was used as the host for gene cloning. E. coli strains were grown at $37^{\circ} \mathrm{C}$ in LuriaBertani (LB) medium (Difco Laboratories, Detroit, MI, USA) or on LB plates solidified with $1.5 \%$ Bacto-agar. Antibiotics were added to the medium if necessary: ampicillin, $100 \mu \mathrm{g} / \mathrm{mL}$ (E. coli), kanamycin, $5 \mu \mathrm{g} / \mathrm{mL}$ (D. radiodurans), and chloramphenicol, $3.8 \mu \mathrm{g} / \mathrm{mL}$ (D. radiodurans).

\subsection{Construction of Mutants and Plasmids}

The $b s h A$ ( $\left.d r_{-} 1555\right)$ and $a b x C$ ( $\left.d r \_1832\right)$ mutant strains were constructed by targeted mutagenesis using the double crossover recombination method described previously [25,26]. Upstream and downstream regions (approximately $1 \mathrm{~kb}$ ) of the coding sequences of target 
genes were amplified by polymerase chain reaction (PCR) using sets of primers carrying restriction sites for cloning (Table S1). Each PCR fragment was digested with the appropriate restriction enzymes (Table S1) and cloned into the corresponding sites of plasmid pKatAPH3 [27]. For transformation with the resulting plasmid, D. radiodurans cells from exponentially growing cultures were collected and concentrated 50-fold in TGY supplemented with $30 \mathrm{mM}$ calcium chloride $\left(\mathrm{CaCl}_{2}\right)$. Cell mixture containing the constructed plasmid DNAs was held on ice and then incubated at $32{ }^{\circ} \mathrm{C}$ for $90 \mathrm{~min}$. The positive mutants were selected on TGY agar plates supplemented with kanamycin as described previously [28]. The disruption of the target genes was confirmed by diagnostic PCR and subsequent DNA sequencing.

The $a b x C$ gene expression plasmid $\mathrm{pAbxC}_{W T}$ was constructed using the pRADZ3 shuttle vector, which contains the groEL promoter for constitutive gene expression and functions both in E. coli and D. radiodurans [8]. This plasmid is present in the cell at approximately the same copy number as the chromosome, which is present at 7 to 10 copies per cell [29]. The complete $a b x C$ coding sequence was PCR-amplified from the genomic DNA of $D$. radiodurans $\mathrm{R} 1$ using 1832-F and 1832-R primers, which carry the ApaI and EcoRV restriction sites, respectively (Table S1). The substitution of cysteine to serine at position 36 (C36S) was introduced into AbxC using the complementary primer pair C36S-F/ R containing the $\mathrm{C} 36 \mathrm{~S}$ mutation (Table S1). Site-directed mutagenesis was performed directly on pAbxC ${ }_{\text {WT }}$ using QuikChange II Site-Directed Mutagenesis Kit ${ }^{\mathrm{TM}}$ (Agilent Technologies, La Jolla, CA, USA). The amplified plasmids (named $\mathrm{pAbxC}_{\mathrm{C} 36 \mathrm{~S}}$ ) were digested with $\mathrm{DpnI}$ and transformed into E. coli DH10B. The C36S substitution was verified by sequencing. The transformed D. radiodurans cells were selected using chloramphenicol $(3.8 \mu \mathrm{g} / \mathrm{mL})$ supplementation.

\subsection{Measurement of $B S H$}

BSHs were measured by high-performance liquid chromatography (HPLC) analysis of fluorescent thiol adducts with monochlorobimane $(\mathrm{mBCl})$, as described previously [30]. Cells grown to $\log$ phase $\left(\mathrm{OD}_{600} \approx 1.0\right)$ were harvested and resuspended in extraction buffer ( $50 \%$ acetonitrile, $2 \mathrm{mM} \mathrm{mBCl}$ and $20 \mathrm{mM}$ Tris- $\mathrm{HCl} \mathrm{pH} \mathrm{8.0).} \mathrm{After} \mathrm{incubation} \mathrm{at} 60^{\circ} \mathrm{C}$ for $15 \mathrm{~min}$, acidification with $25 \mathrm{mM}$ methanesulfonic acid was followed by centrifugation to remove the aggregated proteins. Thiol-bimane conjugates from the supernatants were subjected to HPLC analysis with a fluorescence detector $(\lambda e x=385 \mathrm{~nm}, \lambda \mathrm{em}=460 \mathrm{~nm}$ ) installed in the Agilent 1200 HPLC system (Agilent technologies). ).

\subsection{Survival Assay}

A stationary-phase culture that had grown overnight was inoculated into fresh TGY broth at a 1:100 dilution. Cells grown to $\log$ phase $\left(\mathrm{OD}_{600} \approx 1.0\right)$ in TGY broth without antibiotics were adjusted to $\mathrm{OD}_{600} \approx 0.1$ with TGY and then challenged with 20,40 , and $60 \mathrm{mM} \mathrm{H}_{2} \mathrm{O}_{2}$ for $1 \mathrm{~h}$ at $30^{\circ} \mathrm{C}$. Following treatment with catalase (Sigma-Aldrich, Saint Louis, CA, USA) to remove residual $\mathrm{H}_{2} \mathrm{O}_{2}$, the cells were serially diluted 10 -fold in distilled water and spotted onto solid TGY medium. The TGY plates were incubated at $30{ }^{\circ} \mathrm{C}$ for 2-3 days to enumerate the colony forming units (CFU).

\subsection{Protein Carbonylation Assay}

Cells grown to $\log$ phase $\left(\mathrm{OD}_{600} \approx 1.0\right)$ were treated with 0 or $40 \mathrm{mM} \mathrm{H}_{2} \mathrm{O}_{2}$ for $1 \mathrm{~h}$ and harvested by centrifugation. The cell suspension in phosphate buffered saline (PBS) was lysed by sonication, and the total protein concentration in the supernatants was measured using the Bradford assay. Carbonyl group quantification was performed using the traditional 2,4-dinitrophenylhydrazine (DNPH) method using the Protein Carbonyl Colorimetric Assay Kit (Cayman Chemical, Ann Arbor, MI, USA). Derivatization of protein carbonyls by DNPH was followed by absorbance measurements at $370 \mathrm{~nm}$, according to the manufacturer's instructions. 


\subsection{Protein Purification}

Coding sequences of $a b x C, d r B d r\left(d r \_2623\right), d r O x y R\left(d r \_0615\right), d r \_1022$, and $d r \_1262$ genes were PCR-amplified using the primer pair for each gene (Table S1) and cloned into the $\mathrm{pET}$-21a vector harboring a His $\times 6$ tag at the C-terminus (Novagen, Darmstadt, Germany). In addition, the $a b x C$ gene PCR product was ligated to the plasmid $\mathrm{pET} 28_{\mathrm{FLAG}}$ containing a $3 \times$ FLAG-tag sequence at the N-terminus [31] to produce FLAG-tagged AbxC protein. E. coli BL21-CodonPlus (DE3)-RP strain (Novagen) was transformed with the resulting plasmids and cultivated in LB broth $(0.5 \mathrm{~L})$ with shaking $(200 \mathrm{rpm})$ at $37^{\circ} \mathrm{C}$ until the culture density reached $0.5-0.6$ of $\mathrm{OD}_{600}$. Protein expression was induced with $0.2 \mathrm{mM}$ Isopropyl $\beta$-D-1-thiogalactopyranoside (IPTG), and the cultures were further incubated at $16{ }^{\circ} \mathrm{C}$ for $20 \mathrm{~h}$. Collected cells were suspended in $20 \mathrm{~mL}$ of buffer A $(20 \mathrm{mM}$ Tris- $\mathrm{HCl}$ $\mathrm{pH} 7.5,200 \mathrm{mM} \mathrm{NaCl}$ ) and disrupted by pressuring twice at $40 \mathrm{kpsi}$ using the OS Cell Disrupter (Constant Systems Ltd., Northants, UK). After centrifugation, $15 \mathrm{~mL}$ of crude extract was applied to $5 \mathrm{~mL}$ of Ni-NTA resin (Qiagen, Valencia, CA, USA). The resin was washed with $50 \mathrm{~mL}$ of buffer A containing $30 \mathrm{mM}$ imidazole and eluted with buffer A containing $300 \mathrm{mM}$ imidazole. The samples were concentrated using an Amicon Ultra filter unit (30,000 NMWL, Merck Millipore, Burlington, MA, USA), loaded on a Superdex 75HR column, and eluted with buffer A in an AKTA FPLC system (GE Healthcare Life Science, Boston, MA, USA). The fractions containing the target proteins were verified using sodium dodecyl sulfate-polyacrylamide gel electrophoresis (SDS-PAGE) and concentrated using an Amicon Ultra filter unit (Merck Millipore). Protein concentration was determined using the Bradford method with bovine serum albumin as a standard.

\subsection{NADPH Consumption Assay}

The electron transfer activity of DrBdr with $\mathrm{BSH}$ and $\mathrm{AbxC}$ was determined by measuring NADPH consumption in $50 \mathrm{mM}$ Tris $\mathrm{HCl}(\mathrm{pH} \mathrm{8.0)}$ at room temperature (RT). Reaction mixtures consisting of $500 \mu \mathrm{M}$ NADPH, $500 \mu \mathrm{M}$ BSH (Carbosynth LLC, San Diego, CA, USA), and $0.5 \mu \mathrm{M}$ DrBdr were treated with $10 \mathrm{mM} \mathrm{H}_{2} \mathrm{O}_{2}$ in the absence or presence of $10 \mu \mathrm{M}$ of AbxC. NADPH consumption was monitored immediately after the start of the reaction as absorbance change at $340 \mathrm{~nm}$ using a microplate reader (TECAN, Mannedorf, Switzerland). The reaction was also initiated by adding oxidized AbxC (for a final concentration of $10 \mu \mathrm{M}$ ), which was prepared by incubation with a 10-fold molar excess of thiol-oxidizing agent diamide in $50 \mathrm{mM}$ Tris- $\mathrm{HCl}(\mathrm{pH} 8.0)$ for $60 \mathrm{~min}$ [32].

\subsection{Quantification of Thiols}

Free sulfhydryl (-SH) groups of $\mathrm{AbxC}$ were quantitatively measured using the 5,5dithio-bis-2-nitrobenzoic acid (DTNB) reduction assay. DTNB is reduced by free thiols in an exchange reaction, resulting in the formation of mixed disulfide between analytes and TNB release; hence, it has been used as a classical chromogenic reagent for thiol detection [33]. Purified $\mathrm{AbxC}$ protein was added to $50 \mathrm{mM}$ Tris- $\mathrm{HCl}$ buffer ( $\mathrm{pH} 7.5$ ) containing $2 \mathrm{mM}$ ethylene-diamine-tetraacetic acid (EDTA) to obtain a final concentration of $0.1 \mu \mathrm{M}$ and then treated with different concentrations of $\mathrm{H}_{2} \mathrm{O}_{2}$. The reaction was initiated by adding DTNB (at a final concentration of $10 \mathrm{mM}$ ) at RT, and the increase in absorbance at $412 \mathrm{~nm}$ by 2-nitro-5-thiobnzoic acid (TNB) release was monitored using a microplate reader (TECAN) until fluorescence plateaus were reached. The free -SH concentration was determined by comparison with a standard curve composed of known concentrations of cysteine.

\subsection{Western Blotting}

To express FLAG-tagged AbxC protein in D. radiodurans, the plasmid pKatAPH3 harboring the upstream and downstream regions of $a b x C$ (pKatAPH3-UD1832) used for the $a b x C$ mutant $(\triangle a b x C)$ construction was modified. To introduce the FLAG tag sequence in front of the $a b x C$ ATG codon, in the first step, two fragments were amplified using the primer pairs 1832-Up-F/1832-Flag-R and 1832-Flag-F/1832-R (Table S1) from genomic DNA and pET28 FLAG containing $a b x C$, respectively. In the second step, the two PCR 
products were annealed at their overlapping homologous regions and amplified using the 1832-Up-F/1832-R primer pair. The fusion PCR product was cloned into pKatAPH3UD1832. A kanamycin-resistance gene cassette of the resulting plasmid was swapped with a chloramphenicol-resistance gene cassette from pKatCAT5 [34] by EcoRV and BamHI digestion and subsequent ligation. The plasmid with the sequential array of the upstream region of $a b x C, a b x C$ with a FLAG epitope on the $\mathrm{N}$-terminus, chloramphenicol resistance gene, and downstream region of $a b x C$ was introduced into $\triangle a b x C$.

For Western blot analysis, $D$. radiodurans cells expressing FLAG-tagged AbxC were grown in TGY medium to $\mathrm{OD}_{600} \approx 1.0$, harvested by centrifugation, and then resuspended in PBS. Following sonication for cell lysis, the total protein concentration in the supernatants was measured using the Bradford assay. Total protein $(5 \mu \mathrm{g})$ was resolved by SDS-PAGE under non-reducing conditions and subsequently transferred to a polyvinylidene fluoride (PVDF) membrane in a Mini Trans-Blot Cell (Bio-Rad, Hercules, CA, USA) at $100 \mathrm{~V}$ for $2 \mathrm{~h}$ in Novex Bolt ${ }^{\mathrm{TM}}$ transfer buffer (Thermo Scientific, Waltham, MA, USA). After blocking in 5\% skim milk in Tris-buffered saline with Tween 20 (TBS-T) for $1 \mathrm{~h}$ at RT, the PVDF membrane was incubated with mouse anti-FLAG antibody (1:5000; cat. no. F2555; Sigma-Aldrich; Merck KGaA) for $1 \mathrm{~h}$ at RT and sequentially probed with horseradish peroxide (HRP)conjugated rabbit anti-mouse IgG antibody (1:5000; cat. no. A9044; Sigma-Aldrich). The secondary antibody was detected using a tetramethylbenzidine (TMB) substrate reagent according to the manufacturer's instructions (BD Biosciences, San Jose, CA, USA). The chemiluminescent signals on the PVDF membrane were visualized using a ChemiDoc image system (Bio-Rad). Far-Western blotting was performed as described above, except that $5 \mu \mathrm{g}$ of each purified protein DrOxyR, DR_1022, and DR_1262 was loaded on a 12\% SDS-PAGE gel and incubated with FLAG-tagged AbxC $(0.21 \mathrm{nM})$ at $25^{\circ} \mathrm{C}$ for $2 \mathrm{~h}$ after transfer. Following washing with TBS-T three times, the PVDF membrane was incubated with mouse anti-FLAG antibody (1:5000) for $1 \mathrm{~h}$ at RT and sequentially probed with HRPconjugated rabbit anti-mouse IgG antibody (1:5000). The secondary antibody was detected using the TMB substrate reagent (BD Biosciences) [35].

\subsection{Preparation of AbxC Affinity Column and Capturing of Target Proteins}

AbxC was immobilized on a resin and used to capture potential target proteins in cellular extracts. The affinity column of $\mathrm{AbxC}$ was prepared according to the procedure of Sturm et al. (2009) [36]. D. radiodurans cell lysate $(10 \mathrm{mg})$ from an exponential phase culture was incubated with AbxC-bound beads overnight at $4{ }^{\circ} \mathrm{C}$. Beads were washed with $100 \mathrm{mM}$ Tris ( $\mathrm{pH}$ 8.0) containing $0.5 \mathrm{M} \mathrm{NaCl}$ and then eluted using $10 \mathrm{mM}$ dithiothreitol (DTT). Proteins in the eluate were separated using 12\% SDS-PAGE. The bands of interest were excised from the gel and digested in-gel with trypsin. The eluted peptides were analyzed by nanoscale liquid chromatography-tandem mass spectrometry (nLC-MS-MS) using a dual-cell linear ion trap Orbitrap mass spectrometer (LTQ Velos; Thermo Scientific) installed at the National Center for Interuniversity Research Facilities (NCIRF) at Seoul National University (Seoul, Korea). Proteins were identified by searching the MS/MS spectra against a protein database of $D$. radiodurans using SEQUEST (version 27, Thermo Scientific) $[37,38]$.

\section{Results and Discussions}

\subsection{A BSH-Deficient D. radiodurans Strain Is Sensitive to $\mathrm{H}_{2} \mathrm{O}_{2}$}

In D. radiodurans, three Bsh enzymes BshA (DR_1555), BshB (DR_2363a; WP_01088899 1.1), and BshC (DR_1647) are known to be responsible for BSH biosynthesis [10]. We deleted the $b s h A$ gene in $D$. radiodurans to construct a BSH-deficient strain $(\triangle b s h A)$. $\triangle b s h A \operatorname{did}$ not show any alteration in growth in comparison to the wild-type $D$. radiodurans strain (WT) under normal conditions (Figure S3). When cells were labeled with monochlorobimane $(\mathrm{mBCl}), \mathrm{BSH}$ formed a complex with $\mathrm{mBCl}$ to generate the monobromobimane derivative of BSH [16]. The BSH-bimane derivative peak was observed at $19 \mathrm{~min}$ in the WT cell extracts but disappeared in the HPLC chromatogram of $\triangle b s h A$ (Figure 2A), indicating 
that $\mathrm{BSH}$ production was abolished in $\triangle b s h A$. The protective role of $\mathrm{BSH}$ in response to oxidative stress was estimated by measuring the survival rate of $\Delta b s h A$ following $\mathrm{H}_{2} \mathrm{O}_{2}$ treatment. $\Delta b s h A$ was more sensitive to $\mathrm{H}_{2} \mathrm{O}_{2}$ than WT; $\Delta b s h A$ showed an approximately 1-log reduction in cell survival compared to that of WT in the presence of $40 \mathrm{mM} \mathrm{H}_{2} \mathrm{O}_{2}$ (Figure 2B), suggesting that $\mathrm{BSH}$ is involved in the antioxidant systems of $D$. radiodurans. This result is consistent with the observation that $S$. aureus $b s h A$ mutants are sensitized to exogenous $\mathrm{H}_{2} \mathrm{O}_{2}$ [39].
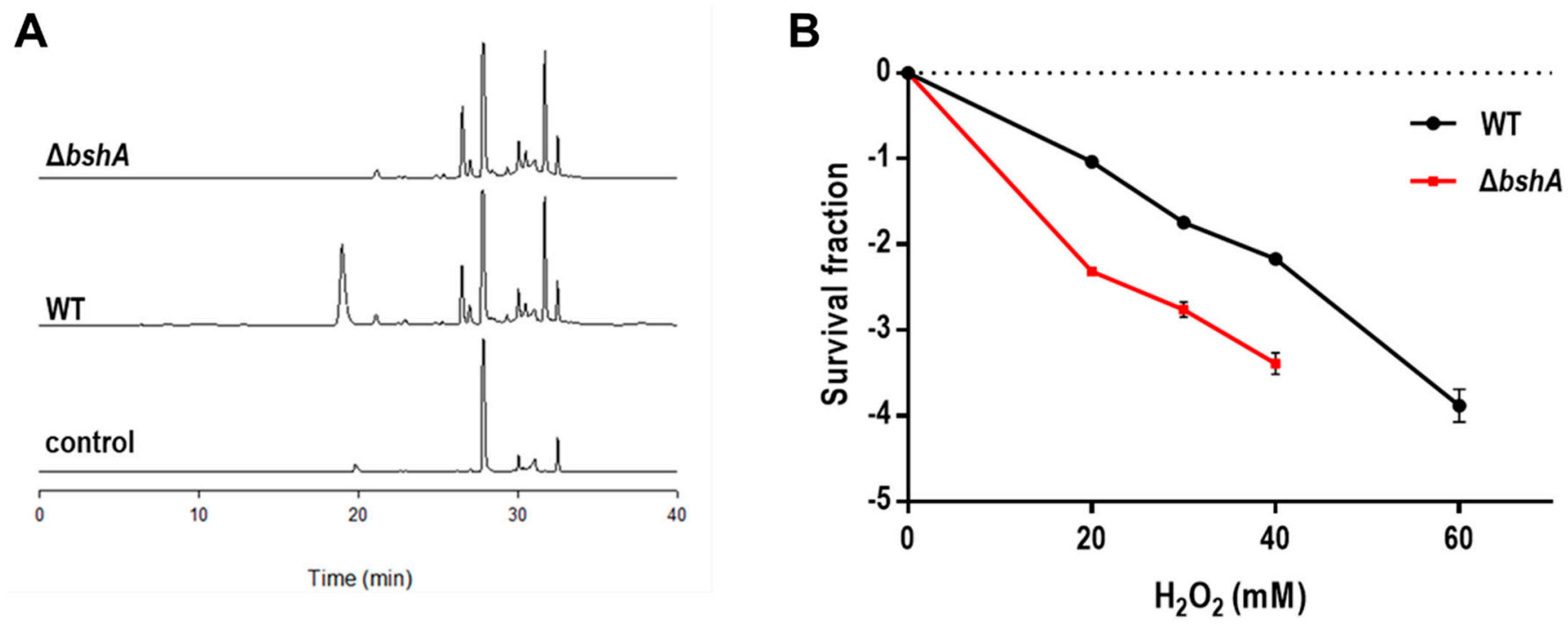

Figure 2. Characterization of $D$. radiodurans bshA mutant strain $(\triangle b s h A)$. (A) Representative HPLC analysis of BSH in the D. radiodurans wild-type strain $(\mathrm{WT})$ and $\triangle b s h A$. BSH was derivatized with monochlorobimane $(\mathrm{mBCl})$ and analyzed by HPLC. Cell extraction buffer was used as control. The HPLC analysis of cellular thiols was repeated two times, with no significant difference in the results. (B) Survival of $\Delta b s h A$ exposed to $\mathrm{H}_{2} \mathrm{O}_{2}$. WT and $\Delta b s h A$ were treated with $\mathrm{H}_{2} \mathrm{O}_{2}$ at the indicated concentrations for $1 \mathrm{~h}$. The survival fraction was calculated by dividing the colony forming units $(\mathrm{CFU})$ of $\mathrm{H}_{2} \mathrm{O}_{2}$ treated cells by the CFU of non-treated cells. Values are means and standard deviations of two independent experiments conducted in duplicate.

\subsection{Mutation of abxC Decreases $\mathrm{H}_{2} \mathrm{O}_{2}$ Resistance of D. radiodurans}

To investigate the role of $\mathrm{AbxC}$ in response to $\mathrm{H}_{2} \mathrm{O}_{2}$, we constructed a $a b x \mathrm{C}$ mutant strain $(\triangle a b x C)$ and examined its survival rates under oxidative stress conditions. The viability of $\triangle a b x \mathrm{C}$ cells was lower than that of the WT following $\mathrm{H}_{2} \mathrm{O}_{2}$ treatment (Figure 3A). The carbonyl content was increased in $\triangle a b x C$ relative to that in WT by $40-\mathrm{mM}$ $\mathrm{H}_{2} \mathrm{O}_{2}$ treatment (Figure $3 \mathrm{~B}$ ). We constructed an expression plasmid producing $\mathrm{AbxC}$ and used this construct to complement the $\triangle a b x C$ strain. Complementation by plasmid-borne $a b x C$ in trans restored the WT level of growth in $\triangle a b x C$ (Figure 3C). AbxC contained only one Cys residue in the putative catalytic motif (Figure 1B). The Cys residue (Cys36) of $\mathrm{AbxC}$ was substituted with serine using site-directed mutagenesis. When the engineered protein harboring $\mathrm{C} 36 \mathrm{~S}$ was provided in trans, it failed to restore the survival ability of $\triangle a b x C$ exposed to $\mathrm{H}_{2} \mathrm{O}_{2}$ to WT levels (Figure $3 \mathrm{C}$ ). These results suggest that the Trx-like protein $\mathrm{AbxC}$ contributes to D. radiodurans resistance to oxidative stress, and Cys36 plays a crucial role in the anti-oxidative function of AbxC. 
A

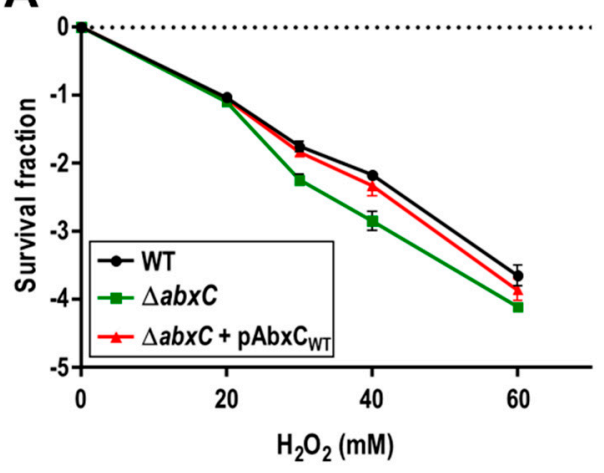

B

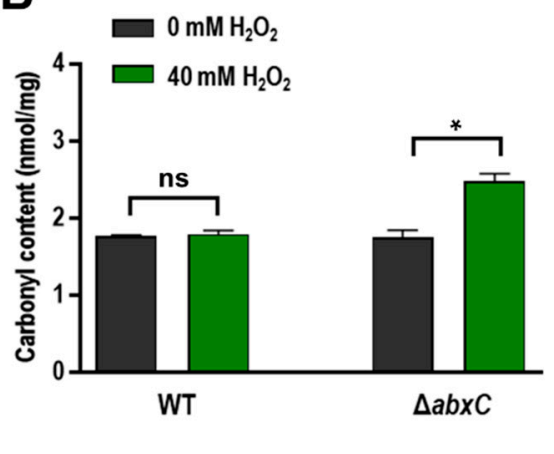

C

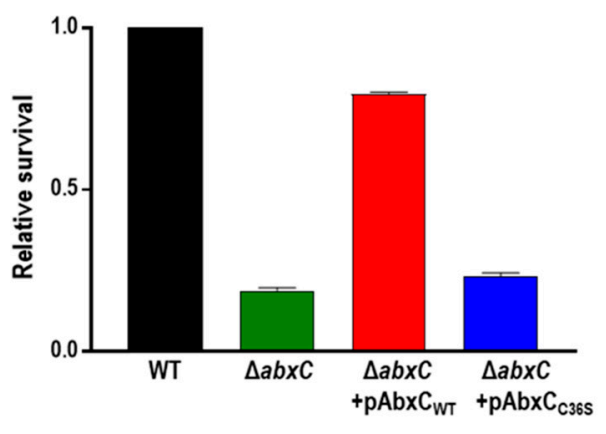

Figure 3. Effects of $a b x C$ mutation on $\mathrm{H}_{2} \mathrm{O}_{2}$ resistance. (A) Survival of $\Delta a b x C$ exposed to $\mathrm{H}_{2} \mathrm{O}_{2}$. WT, $\Delta a b x C$, and $\Delta a b x C$ harboring $\mathrm{pAbxC} \mathrm{CT}_{\mathrm{WT}}$ that encodes the wild-type $\mathrm{AbxC}$ were treated with $\mathrm{H}_{2} \mathrm{O}_{2}$ at the indicated concentrations for $1 \mathrm{~h}$. The survival fraction was calculated by dividing the CFU of $\mathrm{H}_{2} \mathrm{O}_{2}$-treated cells by the CFU of non-treated cells. Values are means and standard deviations of two independent experiments conducted in duplicate. (B) Protein carbonylation of $\triangle a b x C$ in response to $\mathrm{H}_{2} \mathrm{O}_{2}$. After treatment of $40 \mathrm{mM} \mathrm{H}_{2} \mathrm{O}_{2}$ for $1 \mathrm{~h}$, the carbonylated protein contents of WT and $\triangle a b x \mathrm{C}$ were measured by the 2,4-dinitrophenylhydrazine (DNPH) assay. Data represent the means \pm standard deviations of three independent experiments. Comparisons between two groups were performed by Student's t-test (GraphPad Prism 7.04). A $p$-value of less than 0.01 is considered statically significant (ns; not significant, $\left.{ }^{*} ; p<0.01\right)$. (C) Complementation of $\Delta a b x C$.

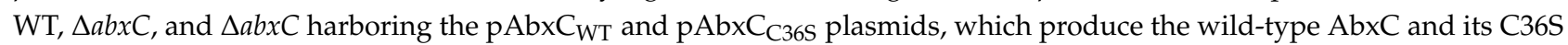
mutant proteins, respectively, were treated with $40 \mathrm{mM} \mathrm{H}_{2} \mathrm{O}_{2}$ for $1 \mathrm{~h}$. Survival abilities of $\triangle a b x \mathrm{C}$ mutants were expressed relative to WT survival (arbitrarily set at 1), i.e., the CFU of mutants were normalized to the CFU of WT. Data represent the means \pm standard deviations of three independent experiments.

\subsection{AbxC Exhibits $\mathrm{H}_{2} \mathrm{O}_{2}$ Scavenging Activity}

BSH reacts directly with ROS, leading to the oxidation of BSH to BSSB [18]. Bacillus and Staphylococcus Bdr proteins have been recently shown to function as NADPH-dependent BSSB reductase $[17,23,24]$. To examine the BSSB reductase activity of DR_2623, a putative Bdr homolog, we analyzed the catalytic activity of purified DR_2623 (here designated DrBdr) in a BSH/NADPH-coupled assay in the presence of $\mathrm{H}_{2} \mathrm{O}_{2}$. The purified DrBdr had the characteristic yellow color of FAD-containing enzymes. Only a small amount of $\mathrm{NADPH}$ was consumed in the presence of BSH (Figure 4A). Interestingly, however, the addition of $\mathrm{AbxC}$ resulted in significant and fast consumption of NADPH as measured by a rapid absorbance decrease at $340 \mathrm{~nm}$ (Figure 4A). Cys36, residing in the conserved TCHKT motif, is the sole cysteine of AbxC (Figure 1B). The DTNB assay for thiol detection showed that $\mathrm{AbxC}$ lost its free thiols upon $\mathrm{H}_{2} \mathrm{O}_{2}$ treatment (Figure $4 \mathrm{~B}$ ), suggesting that AbxC could catalyze $\mathrm{H}_{2} \mathrm{O}_{2}$ reduction. Although DrBdr seemed to have no effect on BSSB reduction in the absence of $\mathrm{AbxC}$, this could be attributed to the fact that the oxidation of $\mathrm{BSH}$ by ROS is strongly influenced by the reduction potential of oxidants [18]. In contrast to the strong oxidant hypochlorous acid $(\mathrm{HOCl})$, which oxidizes $\mathrm{BSH}$ to mostly $\mathrm{BSSB}(70 \%)$, $\mathrm{H}_{2} \mathrm{O}_{2}$ oxidizes only about $10 \%$ of $\mathrm{BSH}$ to exclusively BSSB under the given experimental conditions [18]. In our assays, AbxC significantly enhanced NADPH consumption by DrBdr in response to oxidative stress induced by $\mathrm{H}_{2} \mathrm{O}_{2}$, and the NADPH consumption did not take place when either DrBdr or BSH was absent in the assay (Figure 4A and Figure S4). These results suggest that DrBdr has BSSB reductase activity and acts in the $\mathrm{AbxC} / \mathrm{BSH} / \mathrm{DrBdr}$ redox cycle for $\mathrm{BSH}$ regeneration. 
A

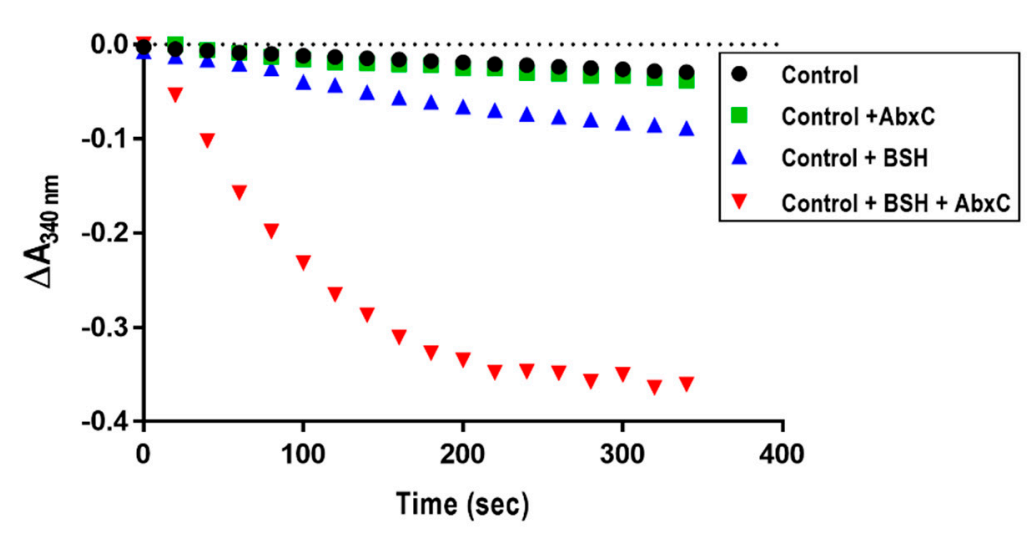

B

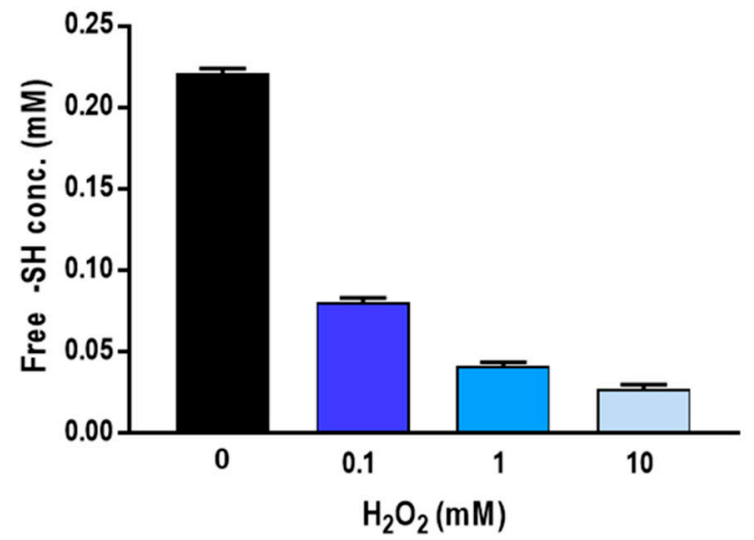

Figure 4. AbxC oxidation by scavenging $\mathrm{H}_{2} \mathrm{O}_{2}$. (A) NADPH consumption by the $\mathrm{DrBdr} / \mathrm{BSH} / \mathrm{AbxC}$ pathway. The control reaction mixture contained $500 \mu \mathrm{M}$ NADPH and $0.5 \mu \mathrm{M}$ DrBdr (DR_2623), and $500 \mu \mathrm{M}$ BSH and/or $10 \mu \mathrm{M}$ AbxC were added in the control mixture. The NADPH consumption was monitored at $340 \mathrm{~nm}$ immediately after addition of $10 \mathrm{mM} \mathrm{H}_{2} \mathrm{O}_{2}$. The experiments were repeated twice and representative data are shown. (B) Evaluation of free thiols (-SH) of $\mathrm{AbxC}$. The purified $\mathrm{AbxC}(0.1 \mu \mathrm{M})$ treated with $0.1,1$, and $10 \mathrm{mM} \mathrm{H}_{2} \mathrm{O}_{2}$ was incubated with $10 \mathrm{mM}$ DTNB solution. The TNB ${ }^{2-}$ ions released during these reactions were monitored by visible spectroscopy at $412 \mathrm{~nm}$. The $-\mathrm{SH}$ concentrations were quantified by the use of a cysteine standard curve. Data represent the means \pm standard deviations of three independent experiments.

\section{4. $\mathrm{H}_{2} \mathrm{O}_{2}$ Stimulates AbxC Dimerization}

To reveal the state of $\mathrm{Cys}$ in $\mathrm{AbxC}$ under oxidative stress conditions, $\mathrm{AbxC}$ was treated with $\mathrm{H}_{2} \mathrm{O}_{2}$, and the products were analyzed by non-reducing SDS-PAGE. Two bands for $\mathrm{AbxC}$ were observed in the absence of $\mathrm{H}_{2} \mathrm{O}_{2}$ (Figure $5 \mathrm{~A}$ ). The molecular weights of the upper and lower bands were equivalent to those of the $\mathrm{AbxC}$ monomer $(23.7 \mathrm{kDa})$ and its homo-dimer $(47.4 \mathrm{kDa})$, respectively (Figure $5 \mathrm{~B})$. The density of the upper band was increased, and that of the lower band was reduced in an $\mathrm{H}_{2} \mathrm{O}_{2}$-dependent manner (Figure 5A). This indicated that $\mathrm{H}_{2} \mathrm{O}_{2}$ oxidized the $\mathrm{AbxC}$ thiols (Cys36) to unstable Cys sulfenic acid intermediates (Cys-SOH), leading to $\mathrm{AbxC}$ dimerization through the formation of intermolecular disulfide bonds. This was supported by the disappearance of the upper band by the addition of a disulfide reducing agent dithiothreitol (DTT) (Figure 5A). The oxidized $\mathrm{AbxC}$ dimers prepared by incubation with excessive diamide were subjected to the analytical method of non-reducing SDS-PAGE gel. The electron transfer reaction including BSH, DrBdr, and NADPH resulted in a decrease in the density of the upper band, with a concomitant increase in the density of the lower band (Figure 5B). In addition, NADPH consumption was observed during the reaction (Figure $5 \mathrm{C}$ ). These results demonstrate that recycling oxidized $\mathrm{AbxC}$ requires the $\mathrm{BSH} / \mathrm{DrBdr} / \mathrm{NADPH}$ redox pathway.

Under oxidizing conditions, the Corynebacterium glutamicum MSH peroxidase (Mpx) is recycled by the mycoredoxin (Mrx)/MSH/MSH disulfide reductase (Mtr) and/or Trx/TrxR electron pathways [40]. The glutathione peroxidase (Gpx) is recycled by GSH. The reduction of oxidized Gpx begins with a reaction with GSH to form GS-Gpx, and the removal of GSH from Gpx occurs either directly via a thiol-disulfide exchange reaction with another GSH molecule or is catalyzed by Grx [41]. The reduction mechanism of AbxC seems different from that of thiol-based antioxidant enzymes. AbxC was oxidized by $\mathrm{H}_{2} \mathrm{O}_{2}$ to form disulfide-bonded dimers, which could be reduced directly by BSH in conjunction with DrBdr (Figures 4 and 5). BSH ionization is one of the unusual biophysical properties of BSH. BSH has a lower thiol pKa value than Cys or GSH, such that the availability of the reactive thiolate form $\left(\mathrm{BS}^{-}\right)$of $\mathrm{BSH}$ required for thiol-disulfide exchange reactions is not limited at physiological $\mathrm{pH}$ [42]. Thus, it is possible that $\mathrm{BSH}$ acts as a nucleophilic thiol available for reaction with disulfides such as DTT. BSH was able to convert the AbxC dimer to its monomeric form in a concentration-dependent manner even in the absence of 
DrBdr (Figure 5D), which confirmed that oxidized AbxC is non-enzymatically reduced by $\mathrm{BSH}$. Further research is needed to delineate the mechanism underlying $\mathrm{AbxC}$ reduction.

A

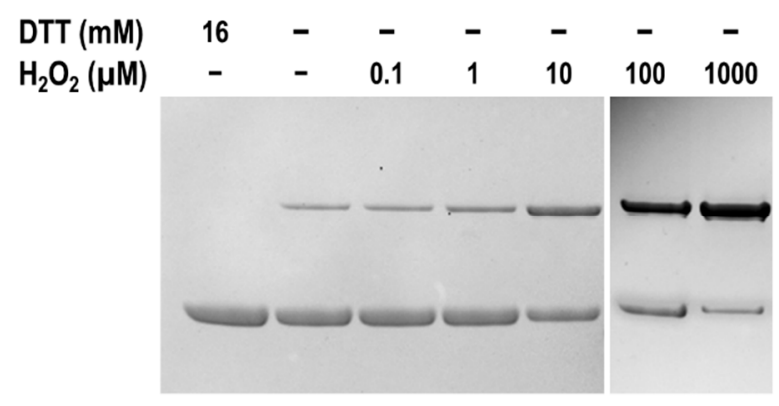

C

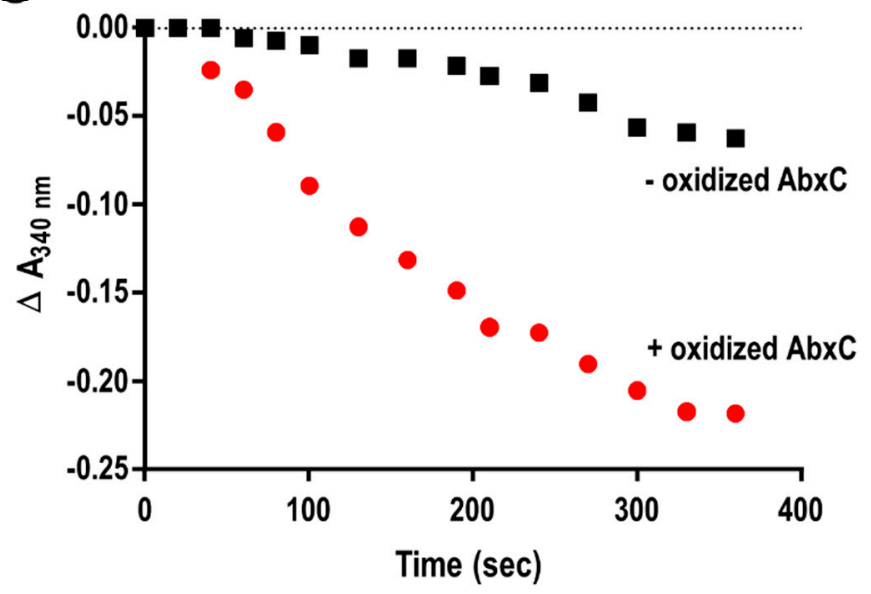

B

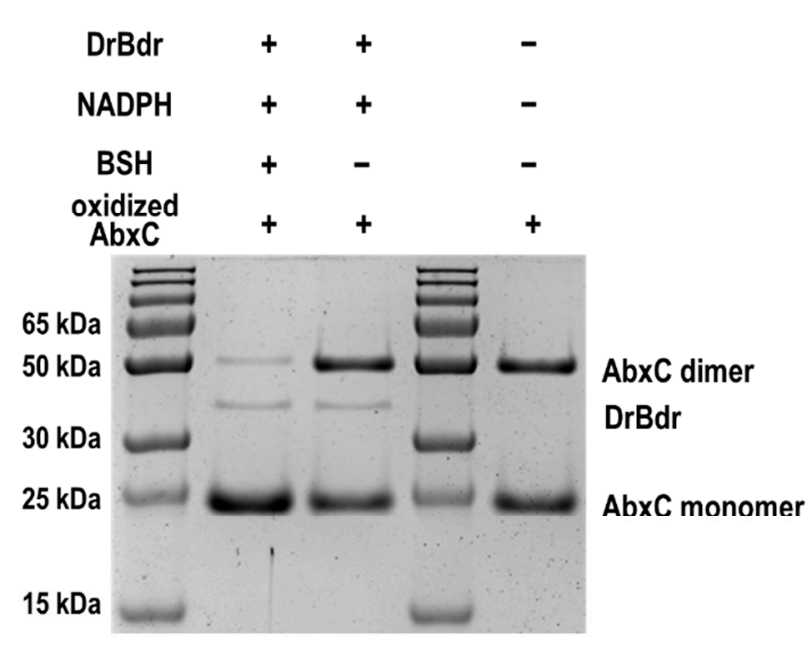

D

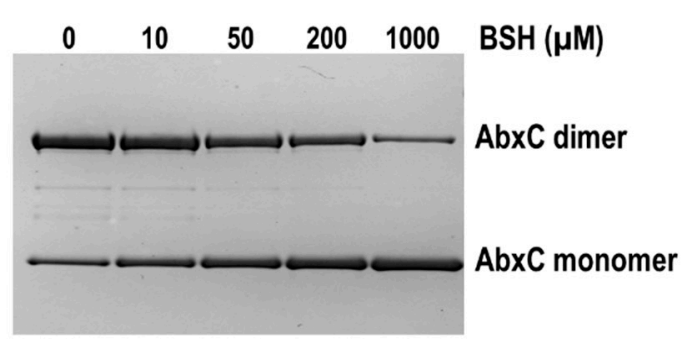

Figure 5. Dimer-monomer transition property of AbxC. (A) Effect of $\mathrm{H}_{2} \mathrm{O}_{2}$ on AbxC oxidation. The purified AbxC proteins $(0.5 \mathrm{mg} / \mathrm{mL})$ were incubated with increasing concentrations of $\mathrm{H}_{2} \mathrm{O}_{2}$ in PBS for $15 \mathrm{~min}$ and then separated using nonreducing SDS-PAGE (12\% gels). DTT was used for AbxC reduction. (B) Effect of BSH in reduction of oxidized AbxC. AbxC proteins $(0.5 \mathrm{mg} / \mathrm{mL})$ oxidized by diamide treatment were incubated alone or with $\operatorname{DrBdr}(0.5 \mu \mathrm{M}) / \mathrm{NADPH}(500 \mu \mathrm{M}) / \mathrm{BSH}$ $(500 \mu \mathrm{M})$ for $15 \mathrm{~min}$ in $20 \mathrm{mM}$ Tris-HCl pH 7.5 at room temperature. The samples were analyzed by non-reducing SDS/PAGE. Bands representing the AbxC monomers and dimers and DrBdr are indicated. (C) NADPH consumption by oxidized AbxC. The reaction mixtures contained $500 \mu \mathrm{M}$ BSH, $500 \mu \mathrm{M}$ NADPH, and $0.5 \mu \mathrm{M}$ DrBdr. Time-dependent consumption of NADPH was monitored at $340 \mathrm{~nm}$ immediately after addition of AbxC (- oxidized AbxC) or oxidized AbxC (+ oxidized $\mathrm{AbxC}$ ). The experiments were repeated twice and representative data are shown. (D) Effect of BSH on AbxC reduction. AbxC proteins $(0.5 \mathrm{mg} / \mathrm{mL})$ were oxidized by diamide treatment and incubated with the indicated concentrations of BSH for $15 \mathrm{~min}$ in $20 \mathrm{mM}$ Tris- $\mathrm{HCl}$ containing $500 \mu \mathrm{M}$ NADPH. The mixtures were separated using non-reducing SDS-PAGE (12\% gels).

\subsection{Identification of Proteins Potentially Interacting with AbxC}

As $\mathrm{AbxC}$ was able to form intermolecular disulfide bonds in vitro even in the absence of $\mathrm{H}_{2} \mathrm{O}_{2}$ (Figure 5), we examined whether $\mathrm{AbxC}$ could interact with other proteins. FLAGtagged $\mathrm{AbxC}$ was introduced into the chromosome of the $\triangle a b x \mathrm{C}$ strain, and whole cell lysates were analyzed by Western blotting. Some protein bands that were not seen in $\triangle a b x C$ were detected by the antibody to FLAG tag in $\triangle a b x C$ expressing FLAG-tagged $\mathrm{AbxC}$, and these bands disappeared after DTT treatment (Figure S5). This suggests that several $D$. radiodurans proteins are physically associated with $\mathrm{AbxC}$, probably through disulfide bond formation. To identify the $\mathrm{AbxC}$-interacting proteins, $\mathrm{AbxC}$ was bound to $\mathrm{CNBr}$-activated beads to generate an affinity column, and cell lysates were incubated with AbxC-bound beads. The protein elution with DTT was followed by SDS-PAGE analysis 
(Figure 6). Bands detected on the gel were excised and subjected to LC-MS/MS analysis. Twenty-five putative AbxC-linked proteins, including AbxC itself, were identified (Table 1).

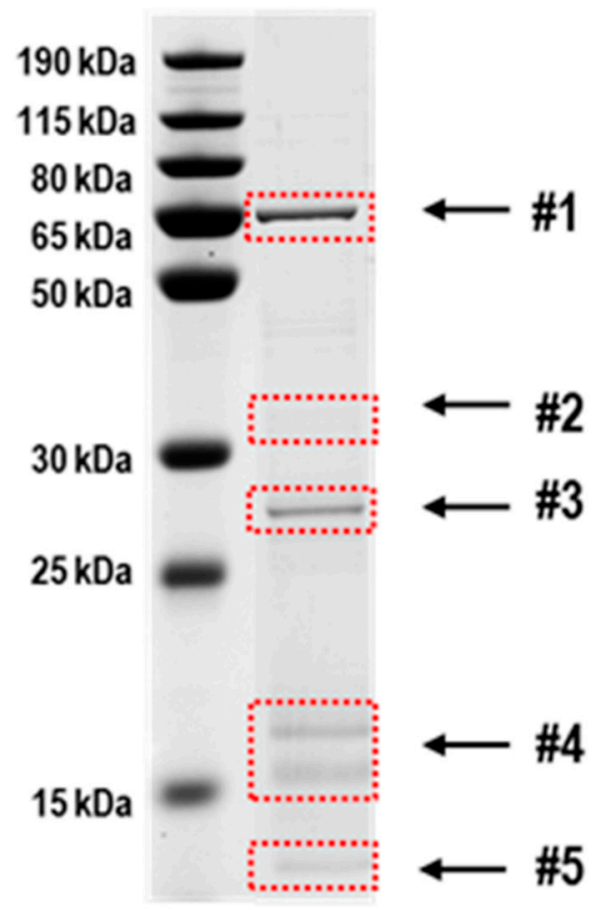

Figure 6. SDS-PAGE profile of the captured proteins by AbxC-affinity chromatography. AbxC was immobilized on $\mathrm{CNBr}$-activated Sepharose $4 \mathrm{~B}$ resin, incubated with $D$. radiodurans cell lysates, and washed with $\mathrm{NaCl}$-containing buffer. Proteins captured by AbxC were released by $10 \mathrm{mM}$ DTT and then separated on SDS-PAGE. Protein bands were identified after tryptic digestion by mass spectrometry. Table 1 is a complete list of protein bands.

Overall, the target proteins are involved in diverse metabolic pathways, including glycolysis (DR_1742), NAD ${ }^{+}$generation (DR_2428), amino acid metabolism (DR_0814, DR_1451, DR_1519), lipid metabolism (DR_1072,DR_1316, DR_A0143), etc. Among them, glucose-6-phosphate isomerase and proline dehydrogenase have been shown to play roles in protecting cells from oxidative stress in E. coli $[43,44]$. DR_1298 belongs to the radical-SAM (S-adenosyl-L-methionine) superfamily of enzymes, which cleaves SAM to methionine and a potent oxidant $5^{\prime}$-deoxyadenosyl radical [45]. The members of radicalSAM enzymes contain a redox-active [4Fe-4S] cluster ligated by three cysteine residues [45]. It has been hypothesized that BSH plays a role in the Fe-S cluster assembly [19]. One of the prominent family expansions found in Deinococcus is the Nudix family of pyrophosphohydrolases, defined as house-cleaning enzymes [46]. These may contribute to radioresistance by removing the deleterious damage products generated by irradiation [46]. Two (DR_0876 and DR_1776) of 23 Nudix hydrolases encoded by D. radiodurans were captured by AbxC affinity chromatography (Table 1). Several proteins involved in the oxidative stress response of $D$. radiodurans were also putative target proteins of AbxC. DR_1857 is a homolog of the Cys-based thiol-dependent peroxidase Ohr (organic hydroperoxide resistance protein), which functions as a hydroperoxide reductase, converting organic hydroperoxides to less toxic organic alcohols [10,47]. DR_0615 encodes a proposed novel $\mathrm{H}_{2} \mathrm{O}_{2}$-sensing transcriptional regulator, DrOxyR. In contrast to typical 2-Cys OxyR, which is activated via intramolecular disulfide formation, DrOxyR has a single sensing cysteine (Cys210) residue [6]. DR_1262 encodes a Ro60 ortholog, named DrRsr (Ro sixty-related), which binds misfolded non-coding RNAs and contributes to D. radiodurans survival following UV irradiation that can induce ROS generation [48]. Although there is no biochemical information available on DR_1022 encoding a MazG-like nucleotide pyrophosphohydrolase, DR_1022 neighbors the dUTPase DR_2231, which performs housecleaning functions 
within the framework of oxidative stress response [49]. The formation of an intermolecular disulfide bond probably leads to a conformational change in the protein, and cellular reducing factors (Trx or LMW thiols) cleave the disulfide bond, which regulates protein function [50]. In D. radiodurans, IR causes the depletion of BSH, suggesting that BSH is oxidized by IR-induced oxidative stress to maintain cellular redox homeostasis [51]. Since these target proteins are functionally linked to cellular redox status and play roles in antioxidant defense systems, their functions may be affected by redox reactions mediated by $\mathrm{AbxC}$ and/or BSH.

Table 1. Potential AbxC interacting proteins.

\begin{tabular}{|c|c|c|c|c|c|}
\hline Fraction & Locus tag & Protein & Size & Count* & No. of Cys \\
\hline \multirow{4}{*}{$\# 1$} & DR_1262 & 60 kDa SS-A/Ro ribonucleoprotein & $57 \mathrm{kDa}$ & 5 & 2 \\
\hline & DR_1298 & radical SAM superfamily & $58 \mathrm{kDa}$ & 6 & 5 \\
\hline & DR_1316 & propionyl-CoA carboxylase & $57 \mathrm{kDa}$ & 10 & 4 \\
\hline & DR_1742 & glucose-6-phosphate isomerase & $60 \mathrm{kDa}$ & 3 & 2 \\
\hline \multirow{8}{*}{ \#2 } & DR_0615 & transcriptional regulator OxyR & $35 \mathrm{kDa}$ & 3 & 1 \\
\hline & DR_0814 & proline dehydrogenase & $35 \mathrm{kDa}$ & 6 & 2 \\
\hline & DR_1072 & acetyl-CoA acetyltransferase & $41 \mathrm{kDa}$ & 7 & 4 \\
\hline & DR_1022 & NTP pyrophosphatase MazG & $37 \mathrm{kDa}$ & 8 & 3 \\
\hline & DR_1519 & ketol-acid reductoisomerase & $37 \mathrm{kDa}$ & 13 & 3 \\
\hline & DR_1890 & oxidoreductase & $35 \mathrm{kDa}$ & 3 & 4 \\
\hline & DR_2428 & nicotinamide-nucleotide adenylyltransferase & $38 \mathrm{kDa}$ & 3 & 1 \\
\hline & DR_A0143 & 3-hydroxyacyl-CoA dehydrogenase & $38 \mathrm{kDa}$ & 3 & 1 \\
\hline \multirow{3}{*}{ \#3 } & DR_0114 & enoyl-CoA hydratase, putative & $27 \mathrm{kDa}$ & 7 & 2 \\
\hline & DR_1451 & S-adenosylhomocysteine nuclosidase & $25 \mathrm{kDa}$ & 4 & 2 \\
\hline & DR_1832 & putative homolog of $\mathrm{BrxC}(\mathrm{YtxJ})$ & $24 \mathrm{kDa}$ & 13 & 1 \\
\hline \multirow{9}{*}{ \#4 } & DR_0763 & predicted acetyltransferase & $18 \mathrm{kDa}$ & 3 & 1 \\
\hline & DR_0876 & Nudix family & $18 \mathrm{kDa}$ & 3 & 2 \\
\hline & DR_1245 & putative sensory transduction regulator & $19 \mathrm{kDa}$ & 6 & 1 \\
\hline & DR_1418 & signal transduction response regulator & $15 \mathrm{kDa}$ & 5 & 2 \\
\hline & DR_1654 & hypothetical protein & $19 \mathrm{kDa}$ & 5 & 3 \\
\hline & DR_1776 & Nudix family & $19 \mathrm{kDa}$ & 4 & 3 \\
\hline & DR_1857 & organic hydroperoxide reductase & $15 \mathrm{kDa}$ & 3 & 2 \\
\hline & DR_2298 & acyl-CoA thioester hydrolase & $19 \mathrm{kDa}$ & 4 & 2 \\
\hline & DR_2481 & hypothetical protein & $17 \mathrm{kDa}$ & 5 & 1 \\
\hline \#5 & DR_2580 & ribosomal silencing factor RsfS & $13 \mathrm{kDa}$ & 6 & 1 \\
\hline
\end{tabular}

\subsection{AbxC Interacts with DrOxyR}

D. radiodurans is extremely resistant to oxidative stress [6]. Among the potential target proteins of AbxC, DrOxyR, DrRsr, and DR_1022, which are known to be associated with oxidative stress response, were chosen for verification to investigate the $\mathrm{AbxC}$ role relevant to the $\mathrm{H}_{2} \mathrm{O}_{2}$ resistance of $D$. radiodurans. Far-Western blotting was carried out using the recombinant proteins DrOxyR, DrRsr, and DR_1022 to confirm that AbxC interacts with these proteins. Immunoreactive bands were observed in the DrOxyR lane when using FLAG-tagged $\mathrm{AbxC}$ as an overlay protein, while no prominent band was observed in other lanes (Figure 7), indicating a direct interaction between DrOxyR and AbxC. DrOxyR 
proteins do not form intermolecular disulfide linkages with each other, even after $\mathrm{H}_{2} \mathrm{O}_{2}$ treatment, which suggests that DrOxyR can be regulated by modification of the single sensing cysteine residue Cys210 at the post-translational level [6]. Hence, if AbxC interacts with DrOxyR through the formation of a specific disulfide bond between their conserved cysteine residues Cys36 and Cys210, DrOxyR can be turned on and off by AbxC. DrOxyR functions as either a repressor or an activator depending on the redox status of Cys210 [6]. For example, under oxidant stress, oxidized DrOxyR activates katE1, whereas under nonstressed conditions, reduced DrOxyR represses katE1, in which both oxidized and reduced DrOxyR binds to the katE1 promoter [8]. AbxCs in their sulfenic acid form may sequester reduced DrOxyR (DrOxyR-SH) in response to $\mathrm{H}_{2} \mathrm{O}_{2}$ treatment, leading to a relative increase in DrOxyR-SOH and a concomitant rise in KatE1. Therefore, the increased sensitivity to $\mathrm{H}_{2} \mathrm{O}_{2}$ of $\triangle a b x \mathrm{C}$ might be partly attributable to the dysregulation of DrOxyR (Figure $3 \mathrm{~A}$ ). Further research is warranted.

\section{Coomassie blue}

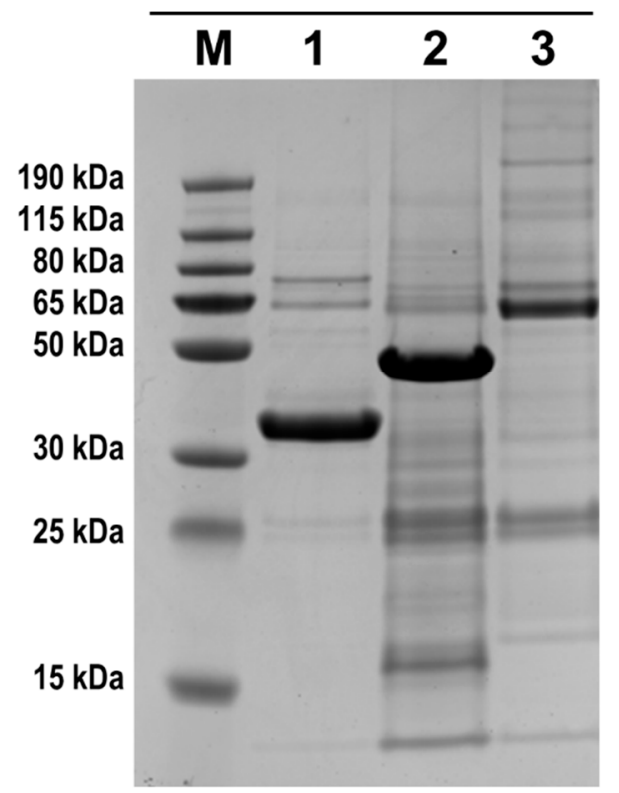

\section{Far-Western blotting}

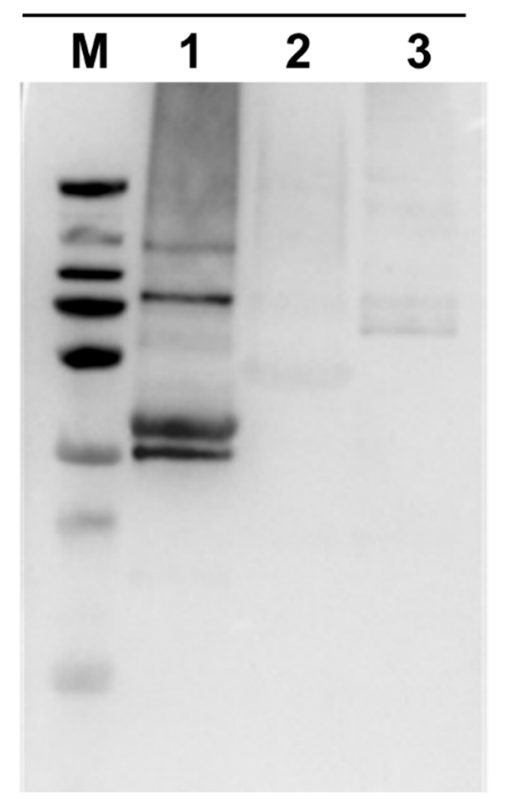

Figure 7. Far-Western blotting of $\mathrm{AbxC}$ and its potential target proteins. The recombinant proteins DrOxyR (lane 1), DR_1022 (lane 2), and DrRsr (lane 3) were separated on SDS-PAGE gels and transferred onto PVDF membranes. The purified FLAG-tagged AbxC served as overlay protein. The left panel shows Coomassie blue staining of target proteins, and the right panel shows the corresponding far-Western blot analysis with anti-FLAG antibody.

\section{Conclusions}

The BSH-dependent redox system consists of NADPH-dependent BSH-specific reductase Bdr, BSH, and BSH-specific oxidoreductase Brx. D. radiodurans produces BSH and encodes putative BSH-related enzymes. The putative Trx reductase DR_2623 (renamed DrBdr) and Trx family enzyme DR_1832 were suggested to be homologs of Bdr and BrxC, respectively [10]. However, DR_1832 differs from the monothiol BrxC in that it has a TCHKT motif instead of the BrxC TCPIS active motif and a colicin-like immunity domain (PF09204) residing in the C-terminal extension. Therefore, here we named DR_1832 AbxC (atypical BrxC). In this study, we found that the AbxC/BSH/DrBdr/NADPH redox pathway was functional and played a role in the antioxidant defense system against $\mathrm{H}_{2} \mathrm{O}_{2}$, in which DrBdr and AbxC showed BSSB disulfide reductase and BSH-dependent peroxidase activities, respectively (Figure 8). Thiol-oxidation of Cys residues by $\mathrm{H}_{2} \mathrm{O}_{2}$ generates Cys$\mathrm{SOH}$ that can either react with LMW thiols, such as MSH and $\mathrm{BSH}$, or lead to the formation of inter- or intramolecular disulfides in proteins [41]. Cys36, within the TCHKT motif, is the sole cysteine residue of $\mathrm{AbxC} . \mathrm{H}_{2} \mathrm{O}_{2}$-treated $\mathrm{AbxC}$ proteins appeared as dimers, 
which were reversible into monomers by BSH, suggesting that disulfide bond formation through Cys36 led to AbxC dimerization. AbxC homologs are present in other bacterial genera, such as Meiothermus and Calidithermus, which are members of Deinococcus-Thermus phylum. The sequence identity between the D. radiodurans $\mathrm{AbxC}$ and the other $\mathrm{AbxCs}$ ranges from $51 \%$ (AbxC of Meiothermus hypogaeus) to $57 \%$ (AbxC of Calidithermus timidus) (data not shown), suggesting that the BSH-dependent peroxidase $\mathrm{AbxC}$ may contribute to the resistance to environmental stresses in these species. In addition, $\mathrm{AbxC}$ interacted with proteins involved in cellular metabolism and the $D$. radiodurans peroxide-sensing transcriptional regulator DrOxyR. This implies that AbxC participates in the $\mathrm{H}_{2} \mathrm{O}_{2}$-signaling pathway. Recently, it was found that B. subtilis BrxC (previously named YtxJ) can catalyze the de-bacillithiolation of several proteins [23]. The possibility of the dual function of AbxC as peroxidase in response to $\mathrm{H}_{2} \mathrm{O}_{2}$ and as $\mathrm{Brx}$ in the de-bacillithiolation pathway cannot be ruled out because $\mathrm{AbxC}$ is the only homolog of Brx found in D. radiodurans. However, it has been suggested that other oxidoreductases, including the essential Trx system, might contribute to de-bacillithiolation in B. subtilis [20]. Therefore, there is a need to identify $S$-bacillithiolated proteins in D. radiodurans and to investigate the role of $\mathrm{AbxC}$ in the removal of $\mathrm{BSH}$ from the proteins.

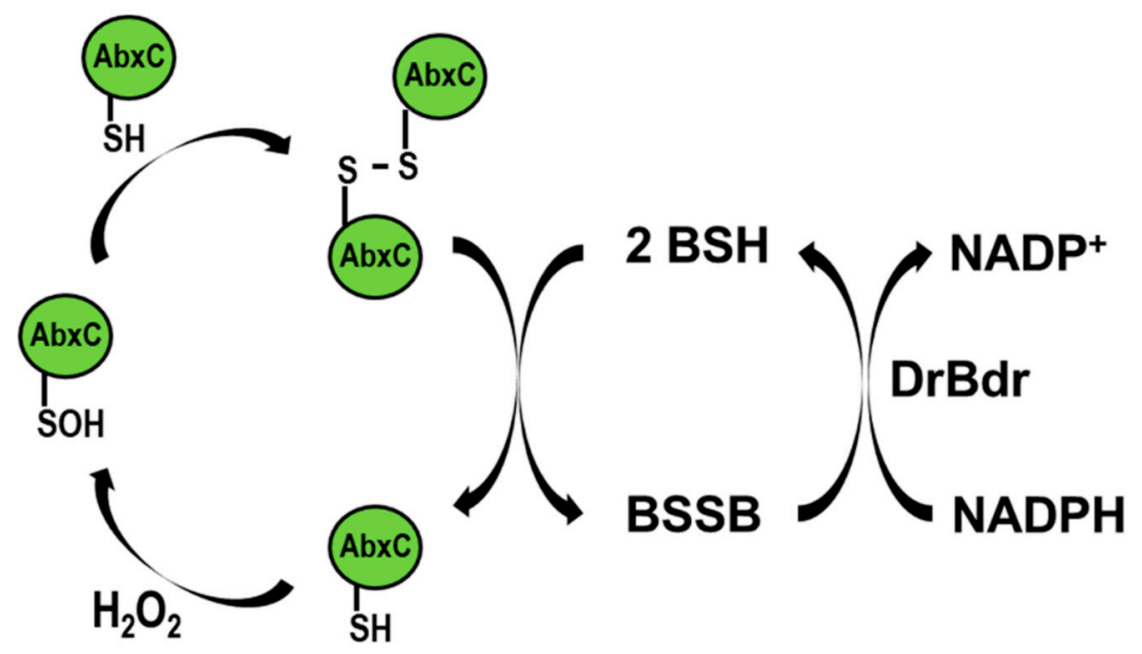

Figure 8. The possible recycling pathway of $\mathrm{AbxC}$. Under $\mathrm{H}_{2} \mathrm{O}_{2}$ stress, oxidation of the $\mathrm{AbxC}$ thiol (AbxC-SH) leads to the formation of a sulfenic acid intermediate of $\mathrm{AbxC}(\mathrm{AbxC}-\mathrm{SOH})$, which can react with another $\mathrm{AbxC}-\mathrm{SH}$ to form an intermolecular disulfide bond. $\mathrm{BSH}$ functions in reduction of the $\mathrm{AbxC}$ dimer to release the active AbxC monomer, resulting in BSSB formation. The BSSB reductase DrBdr regenerates $\mathrm{BSH}$ on expense of $\mathrm{NADPH}$.

Supplementary Materials: The following are available online at https: / www.mdpi.com/article/ 10.3390/antiox10071148/s1, Table S1: Primers used in this study, Figure S1: Multiple alignment of amino acid sequences of D. radiodurans Bdr (DR_2623) and its homologs, Figure S2: Multiple alignment of amino acid sequences of deinococcal AbxC homologs, Figure S3: Growth curve of $b s h A$ mutant, Figure S4: NADPH consumption by the $\mathrm{AbxC} / \mathrm{BSH} / \mathrm{DrBdr}$ pathway in response to $\mathrm{H}_{2} \mathrm{O}_{2}$, and Figure S5: Western blotting of D. radiodurans cells with FLAG-tagged AbxC.

Author Contributions: Conceptualization, S.J., J.-H.J., and Y.-S.B.; methodology, S.J., M.-K.K., and A.d.G.; validation, S.J., Y.-S.B. and S.L.; formal analysis, J.-H.J.; investigation, S.J. and J.-H.J.; resources, A.d.G. and L.B.; data curation, S.R.; writing—original draft preparation, S.J.; writing-review and editing, S.L.; supervision, S.L. and Y.-S.B.; project administration, S.L.; funding acquisition, S.L. All authors have read and agreed to the published version of the manuscript.

Funding: This research was supported by the Nuclear R\&D program and the National Research Foundation of Korea (NRF) grant (No.2020K1A3A1A21039740) funded by the Ministry of Science and ICT (MSIT), Republic of Korea.

Institutional Review Board Statement: Not applicable. 
Informed Consent Statement: Not applicable.

Data Availability Statement: Data is contained within the article and supplementary material.

Conflicts of Interest: The authors declare no conflict of interest.

\section{References}

1. Ezraty, B.; Gennaris, A.; Barras, F.; Collet, J.F. Oxidative stress, protein damage and repair in bacteria. Nat. Rev. Microbiol. 2017, 15, 385-396. [CrossRef] [PubMed]

2. Schieber, M.; Chandel, N.S. ROS function in redox signaling and oxidative stress. Curr. Biol. 2014, 24, R453-R462. [CrossRef]

3. Dalle-Donne, I.; Milzani, A.; Gagliano, N.; Colombo, R.; Giustarini, D.; Rossi, R. Molecular mechanisms and potential clinical significance of S-glutathionylation. Antioxid. Redox Signal. 2008, 10, 445-473. [CrossRef] [PubMed]

4. Zamocky, M.; Gasselhuber, B.; Furtmuller, P.G.; Obinger, C. Molecular evolution of hydrogen peroxide degrading enzymes. Arch. Biochem. Biophys. 2012, 525, 131-144. [CrossRef] [PubMed]

5. Pannala, V.R.; Dash, R.K. Mechanistic characterization of the thioredoxin system in the removal of hydrogen peroxide. Free Radic. Biol. Med. 2015, 78, 42-55. [CrossRef] [PubMed]

6. Chen, H.; Xu, G.; Zhao, Y.; Tian, B.; Lu, H.; Yu, X.; Xu, Z.; Ying, N.; Hu, S.; Hua, Y. A novel OxyR sensor and regulator of hydrogen peroxide stress with one cysteine residue in Deinococcus radiodurans. PLoS ONE 2008, 3, e1602. [CrossRef] [PubMed]

7. Basu, B.; Apte, S.K. Gamma radiation-induced proteome of Deinococcus radiodurans primarily targets DNA repair and oxidative stress alleviation. Mol. Cell Proteomics. 2012, 11. [CrossRef] [PubMed]

8. Jeong, S.W.; Jung, J.H.; Kim, M.K.; Seo, H.S.; Lim, H.M.; Lim, S. The three catalases in Deinococcus radiodurans: Only two show catalase activity. Biochem. Biophys. Res. Commun. 2016, 469, 443-448. [CrossRef]

9. Wood, Z.A.; Schroder, E.; Robin Harris, J.; Poole, L.B. Structure, mechanism and regulation of peroxiredoxins. Trends Biochem. Sci. 2003, 28, 32-40. [CrossRef]

10. Lim, S.; Jung, J.H.; Blanchard, L.; de Groot, A. Conservation and diversity of radiation and oxidative stress resistance mechanisms in Deinococcus species. FEMS Microbiol. Rev. 2019, 43, 19-52. [CrossRef]

11. Zhao, L.; Jeong, S.; Zhang, J.; Jung, J.H.; Choi, J.I.; Lim, S.; Kim, M.K. Crystal structure of the AhpD-like protein DR1765 from Deinococcus radiodurans R1. Biochem. Biophys. Res. Commun. 2020, 529, 444-449. [CrossRef] [PubMed]

12. Obiero, J.; Pittet, V.; Bonderoff, S.A.; Sanders, D.A. Thioredoxin system from Deinococcus radiodurans. J. Bacteriol. 2010, 192, 494-501. [CrossRef] [PubMed]

13. Cho, C.; Lee, G.W.; Hong, S.H.; Kaur, S.; Jung, K.W.; Jung, J.H.; Lim, S.; Chung, B.Y.; Lee, S.S. Novel functions of peroxiredoxin Q from Deinococcus radiodurans R1 as a peroxidase and a molecular chaperone. FEBS Lett. 2019, 593, 219-229. [CrossRef] [PubMed]

14. Wang, M.; Zhao, Q.; Liu, W. The versatile low-molecular-weight thiols: Beyond cell protection. Bioessays 2015, 37, 1262-1267. [CrossRef] [PubMed]

15. Loi, V.V.; Rossius, M.; Antelmann, H. Redox regulation by reversible protein S-thiolation in bacteria. Front. Microbiol. 2015, 6, 187. [CrossRef]

16. Newton, G.L.; Rawat, M.; La Clair, J.J.; Jothivasan, V.K.; Budiarto, T.; Hamilton, C.J.; Claiborne, A.; Helmann, J.D.; Fahey, R.C. Bacillithiol is an antioxidant thiol produced in Bacilli. Nat. Chem. Biol. 2009, 5, 625-627. [CrossRef] [PubMed]

17. Linzner, N.; Loi, V.V.; Fritsch, V.N.; Tung, Q.N.; Stenzel, S.; Wirtz, M.; Hell, R.; Hamilton, C.J.; Tedin, K.; Fulde, M.; et al. Staphylococcus aureus Uses the Bacilliredoxin (BrxAB)/Bacillithiol Disulfide Reductase (YpdA) Redox Pathway to Defend Against Oxidative Stress Under Infections. Front. Microbiol. 2019, 10, 1355. [CrossRef]

18. Dickerhof, N.; Paton, L.; Kettle, A.J. Oxidation of bacillithiol by myeloperoxidase-derived oxidants. Free Radic. Biol. Med. 2020, 158, 74-83. [CrossRef]

19. Chandrangsu, P.; Loi, V.V.; Antelmann, H.; Helmann, J.D. The Role of Bacillithiol in Gram-Positive Firmicutes. Antioxid. Redox Signal. 2018, 28, 445-462. [CrossRef]

20. Gaballa, A.; Chi, B.K.; Roberts, A.A.; Becher, D.; Hamilton, C.J.; Antelmann, H.; Helmann, J.D. Redox regulation in Bacillus subtilis: The bacilliredoxins BrxA(YphP) and BrxB(YqiW) function in de-bacillithiolation of S-bacillithiolated OhrR and MetE. Antioxid. Redox Signal. 2014, 21, 357-367. [CrossRef]

21. Imber, M.; Huyen, N.T.T.; Pietrzyk-Brzezinska, A.J.; Loi, V.V.; Hillion, M.; Bernhardt, J.; Tharichen, L.; Kolsek, K.; Saleh, M.; Hamilton, C.J.; et al. Protein S-Bacillithiolation Functions in Thiol Protection and Redox Regulation of the Glyceraldehyde-3Phosphate Dehydrogenase Gap in Staphylococcus aureus Under Hypochlorite Stress. Antioxid. Redox Signal. 2018, $28,410-430$. [CrossRef]

22. Gaballa, A.; Newton, G.L.; Antelmann, H.; Parsonage, D.; Upton, H.; Rawat, M.; Claiborne, A.; Fahey, R.C.; Helmann, J.D. Biosynthesis and functions of bacillithiol, a major low-molecular-weight thiol in Bacilli. Proc. Natl. Acad Sci. USA 2010, 107, 6482-6486. [CrossRef] [PubMed]

23. Gaballa, A.; Su, T.T.; Helmann, J.D. The Bacillus subtilis monothiol bacilliredoxin BrxC (YtxJ) and the Bdr (YpdA) disulfide reductase reduce S-bacillithiolated proteins. Redox Biol. 2021, 101935. [CrossRef] [PubMed]

24. Hammerstad, M.; Gudim, I.; Hersleth, H.P. The Crystal Structures of Bacillithiol Disulfide Reductase Bdr (YpdA) Provide Structural and Functional Insight into a New Type of FAD-Containing NADPH-Dependent Oxidoreductase. Biochemistry 2020, 59, 4793-4798. [CrossRef] 
25. Joe, M.H.; Lee, K.H.; Lim, S.Y.; Im, S.H.; Song, H.P.; Lee, I.S.; Kim, D.H. Pigment-based whole-cell biosensor system for cadmium detection using genetically engineered Deinococcus radiodurans. Bioprocess. Biosyst. Eng. 2012, 35, 265-272. [CrossRef]

26. Udupa, K.S.; O'Cain, P.A.; Mattimore, V.; Battista, J.R. Novel ionizing radiation-sensitive mutants of Deinococcus radiodurans. J. Bacteriol. 1994, 176, 7439-7446. [CrossRef] [PubMed]

27. Ohba, H.; Satoh, K.; Yanagisawa, T.; Narumi, I. The radiation responsive promoter of the Deinococcus radiodurans pprA gene. Gene 2005, 363, 133-141. [CrossRef]

28. Jeong, S.W.; Kim, M.K.; Zhao, L.; Yang, S.K.; Jung, J.H.; Lim, H.M.; Lim, S. Effects of Conserved Wedge Domain Residues on DNA Binding Activity of Deinococcus radiodurans RecG Helicase. Front. Genet. 2021, 12, 634615. [CrossRef]

29. Meima, R.; Lidstrom, M.E. Characterization of the minimal replicon of a cryptic Deinococcus radiodurans SARK plasmid and development of versatile Escherichia coli-D. radiodurans shuttle vectors. Appl. Environ. Microbiol. 2000, 66, 3856-3867. [CrossRef]

30. Newton, G.L.; Fahey, R.C.; Rawat, M. Detoxification of toxins by bacillithiol in Staphylococcus aureus. Microbiology 2012, 158, 1117-1126. [CrossRef]

31. Seo, H.S.; Xiong, Y.Q.; Mitchell, J.; Seepersaud, R.; Bayer, A.S.; Sullam, P.M. Bacteriophage lysin mediates the binding of streptococcus mitis to human platelets through interaction with fibrinogen. PLoS Pathog. 2010, 6, e1001047. [CrossRef]

32. Moreno-Sanchez, R.; Marin-Hernandez, A.; Gallardo-Perez, J.C.; Vazquez, C.; Rodriguez-Enriquez, S.; Saavedra, E. Control of the NADPH supply and GSH recycling for oxidative stress management in hepatoma and liver mitochondria. Biochim. Biophys. Acta Bioenerg. 2018, 1859, 1138-1150. [CrossRef] [PubMed]

33. Winther, J.R.; Thorpe, C. Quantification of thiols and disulfides. Biochim. Biophys. Acta 2014, 1840, 838-846. [CrossRef] [PubMed]

34. Satoh, K.; Tu, Z.; Ohba, H.; Narumi, I. Development of versatile shuttle vectors for Deinococcus grandis. Plasmid 2009, 62, 1-9. [CrossRef] [PubMed]

35. Wu, Y.; Li, Q.; Chen, X.Z. Detecting protein-protein interactions by Far western blotting. Nat. Protoc. 2007, 2, 3278-3284. [CrossRef] [PubMed]

36. Sturm, N.; Jortzik, E.; Mailu, B.M.; Koncarevic, S.; Deponte, M.; Forchhammer, K.; Rahlfs, S.; Becker, K. Identification of proteins targeted by the thioredoxin superfamily in Plasmodium falciparum. PLoS Pathog. 2009, 5, e1000383. [CrossRef] [PubMed]

37. Hahm, J.Y.; Kim, J.Y.; Park, J.W.; Kang, J.Y.; Kim, K.B.; Kim, S.R.; Cho, H.; Seo, S.B. Methylation of UHRF1 by SET7 is essential for DNA double-strand break repair. Nucleic. Acids. Res. 2019, 47, 184-196. [CrossRef]

38. Kim, J.; Kang, J.; Kang, Y.L.; Woo, J.; Kim, Y.; Huh, J.; Park, J.W. Ketohexokinase-A acts as a nuclear protein kinase that mediates fructose-induced metastasis in breast cancer. Nat. Commun. 2020, 11, 5436. [CrossRef]

39. Posada, A.C.; Kolar, S.L.; Dusi, R.G.; Francois, P.; Roberts, A.A.; Hamilton, C.J.; Liu, G.Y.; Cheung, A. Importance of bacillithiol in the oxidative stress response of Staphylococcus aureus. Infect. Immun. 2014, 82, 316-332. [CrossRef]

40. Pedre, B.; Van Molle, I.; Villadangos, A.F.; Wahni, K.; Vertommen, D.; Turell, L.; Erdogan, H.; Mateos, L.M.; Messens, J. The Corynebacterium glutamicum mycothiol peroxidase is a reactive oxygen species-scavenging enzyme that shows promiscuity in thiol redox control. Mol. Microbiol. 2015, 96, 1176-1191. [CrossRef]

41. Ulrich, K.; Jakob, U. The role of thiols in antioxidant systems. Free Radic. Biol. Med. 2019, 140, 14-27. [CrossRef]

42. Perera, V.R.; Newton, G.L.; Pogliano, K. Bacillithiol: A key protective thiol in Staphylococcus aureus. Expert Rev. Anti. Infect. Ther. 2015, 13, 1089-1107. [CrossRef] [PubMed]

43. Rungrassamee, W.; Liu, X.; Pomposiello, P.J. Activation of glucose transport under oxidative stress in Escherichia coli. Arch. Microbiol. 2008, 190, 41-49. [CrossRef] [PubMed]

44. Zhang, L.; Alfano, J.R.; Becker, D.F. Proline metabolism increases katG expression and oxidative stress resistance in Escherichia coli. J. Bacteriol. 2015, 197, 431-440. [CrossRef] [PubMed]

45. Lanz, N.D.; Booker, S.J. Auxiliary iron-sulfur cofactors in radical SAM enzymes. Biochim. Biophys. Acta 2015, $1853,1316-1334$. [CrossRef]

46. Makarova, K.S.; Aravind, L.; Daly, M.J.; Koonin, E.V. Specific expansion of protein families in the radioresistant bacterium Deinococcus radiodurans. Genetica 2000, 108, 25-34. [CrossRef] [PubMed]

47. Meunier-Jamin, C.; Kapp, U.; Leonard, G.A.; McSweeney, S. The structure of the organic hydroperoxide resistance protein from Deinococcus radiodurans. Do conformational changes facilitate recycling of the redox disulfide? J. Biol. Chem. 2004, 279, 25830-25837. [CrossRef]

48. Chen, X.; Quinn, A.M.; Wolin, S.L. Ro ribonucleoproteins contribute to the resistance of Deinococcus radiodurans to ultraviolet irradiation. Genes Dev. 2000, 14, 777-782.

49. Goncalves, A.M.D.; de Sanctis, D.; McSweeney, S.M. Structural and functional insights into DR2231 protein, the MazG-like nucleoside triphosphate pyrophosphohydrolase from Deinococcus radiodurans. J. Biol. Chem. 2011, 286, 30691-30705. [CrossRef]

50. Nagahara, N. Intermolecular disulfide bond to modulate protein function as a redox-sensing switch. Amino. Acids. 2011, 41, 59-72. [CrossRef]

51. Luan, H.; Meng, N.; Fu, J.; Chen, X.; Xu, X.; Feng, Q.; Jiang, H.; Dai, J.; Yuan, X.; Lu, Y.; et al. Genome-wide transcriptome and antioxidant analyses on gamma-irradiated phases of Deinococcus radiodurans R1. PLoS ONE 2014, 9, e85649. [CrossRef] [PubMed] 